\title{
Integrated approaches for assessment of cellular performance in industrially relevant filamantous fungi
}

\author{
Workman, Mhairi; Andersen, Mikael Rørdam; Thykær, Jette
}

Published in:

Industrial Biotechnology

Link to article, DOI:

10.1089/ind.2013.0025

Publication date:

2013

Document Version

Publisher's PDF, also known as Version of record

Link back to DTU Orbit

Citation (APA):

Workman, M., Andersen, M. R., \& Thykær, J. (2013). Integrated approaches for assessment of cellular performance in industrially relevant filamantous fungi. Industrial Biotechnology, 9(6), 337-344.

https://doi.org/10.1089/ind.2013.0025

\section{General rights}

Copyright and moral rights for the publications made accessible in the public portal are retained by the authors and/or other copyright owners and it is a condition of accessing publications that users recognise and abide by the legal requirements associated with these rights.

- Users may download and print one copy of any publication from the public portal for the purpose of private study or research.

- You may not further distribute the material or use it for any profit-making activity or commercial gain

- You may freely distribute the URL identifying the publication in the public portal

If you believe that this document breaches copyright please contact us providing details, and we will remove access to the work immediately and investigate your claim 


\section{Review}

\section{Integrated Approaches for Assessment of Cellular Performance in Industrially Relevant Filamentous Fungi}

\author{
Mhairi Workman, Mikael R. Andersen, and Jette Thykaer \\ Department of Systems Biology, Technical University of Denmark, \\ Lyngby, Denmark
}

\begin{abstract}
The performance of filamentous fungi in submerged cultivation determines their suitability for large-scale industrial biotechnology processes and is the result of complex interplay between the physical and chemical parameters of the process and the cellular biology of the fungi. Filamentous fungi have a natural ability to degrade complex substrates through secretion of a large number of diverse enzymes and to produce a number of metabolites that inhibit or prevent the growth of other species in the surroundings. These features have been exploited by industry, resulting in multi-billion dollar processes for producing enzymes and metabolites of value. However, the wealth of diversity of these species is still not fully represented in large-scale bioprocesses, and thus advancement from discovery to application is one of the challenges for modern biotechnology. Acceleration of the process can be achieved through integrated approaches for assessing cellular performance (quantitative physiology), genetic modification of strains (metabolic engineering), and omics analyses and modeling (systems biology). In this review, we evaluate stateof-the-art of filamentous fungal applications in industrial biotechnology, focusing on physiological aspects of the fungi that provide the basis of their cellular performance. We also discuss the advancement of systems biology approaches and how the establishment of these tools for fungal research has begun to reveal the possibilities for further exploitation of these organisms. Increased future focus on multicellular physiology and relevant assays will lead to fungal cells and processes that are customizable to a greater degree, finally allowing the full potential of these complex organisms and their product diversity to unfold.
\end{abstract}

\section{Introduction}

I n prokaryotes (such as Escherichia coli) and yeast (such as Saccharomyces cerevisiae), systems biology approaches have been well developed in the post-genomic era- $S$. cerevisiae was sequenced in 1996, followed by $E$. coli in 1997. ${ }^{1-2}$ Quantification of physiological features was achieved by applying a variety of highly advanced techniques and tools for studying and manipulating the biological systems responsible for production of desirable metabolites. Subsequent modeling - in particular, by combining transcriptomic, metabolomic, and proteomic data - provided the necessary basis for powerful advances in our holistic understanding of these organisms. ${ }^{3}$ With more than 1,300 articles in the literature since 2000 that include both the terms "yeast" and "systems biology," the application of systems biology approaches in yeast is clearly well established. Systems biology research involving filamentous fungi lags behind, however, partly because whole genome sequencing of these organisms (Neurospora crassa, Aspergillus oryzae, Aspergillus niger, Trichoderma reesei, Penicillium chrysogenum) took place much later than for other organisms, and partly due to the challenges inherent in working with submerged cultivation (fermentation) of multi-cellular fungi in reproducible and standardized ways - an essential requirement for the statistical methods applied to interpret the "omes."4-8

Much of the research until now has been based on metabolic engineering approaches and genetic manipulation involving single genes, which, while providing valuable data, are not sufficient for integrated systems biology approaches. To advance these approaches in filamentous fungi, further development of models and improved data integration are required. Carefully designed and controlled, reproducible cultivation techniques that produce the tailor-made biomass needed to define cellular physiology under specific conditions are of equal importance. To obtain high-quality data from omics analyses, the cultures must be grown under tightly regulated and controlled conditions, harvested and stored using methods that preserve their metabolic state, and then be processed for use in advanced assays.

Considerable advances in lab-scale fungal cultivation techniques were made over the last 10-15 years as our understanding of how to cultivate organisms for optimal characterization or performance improved. Highly reproducible, replicate bioreactor experiments that provide quality biomass can now be performed with filamentous fungi, thus tackling one of the major challenges in the field. ${ }^{9-13}$ It is therefore not a coincidence that the terms Aspergillus and systems biology are now appearing together with greater frequency in the literature, in 83 articles published since 2007, where the first genomes were published. Although the gap between yeast and filamentous fungi remains, it is clear that systems biology approaches in filamentous fungi are increasing exponentially. In this review, we highlight the progress in quantitative fungal physiology and omics-driven analytical tools and how merging these disciplines can 
accelerate integrated approaches for in-depth characterization of fungal cell factories.

\section{Cellular Performance of Established Fungal Cell Factories}

Filamentous fungi have served as industrial cell factories for more than half a century, and large-scale processes based on these organisms are therefore well established. The broad application of filamentous fungi in industry covers biochemicals, proteins, and pharmaceuticals. ${ }^{14-18}$ Examples include the citric acid production process using $A$. niger and penicillin production using $P$. chrysogenum, in which incremental improvements and new insights have been documented over many decades. ${ }^{15,19-24}$ The characterization of filamentous fungal hosts for expression of proteins also dominates the literature, and this field has been thoroughly reviewed in recent years. ${ }^{18,25}$

\section{CELL FACTORY CHARACTERISTICS}

While Penicillium is still recognized for its production of various beta-lactams in very high yields, the genus Aspergillus is widely used in industry for the production of both organic acids and enzymes. ${ }^{25-26} T$. reesei is the organism of choice for production of cellulolytic enzymes, as it exhibits high levels of secretion and harbors more than 200 genes for polysaccharidedegrading enzymes. ${ }^{27}$ Organism specialization is, of course, partly dependent on the genetic background. Penicillium species have been domesticated for large-scale antibiotic production through intense strain improvement programs and selection for morphological types that ease cultivation and processing. ${ }^{28}$ Aspergilli have been exploited for their production and secretion of organic acids; they are particularly attractive for this application because they tolerate low $\mathrm{pH}$ and process conditions can determine which acid(s) are produced. The versatility of this genus is further underlined by the fact that Aspergilli are used to produce more than $60 \%$ of the industrial enzymes made with filamentous fungi. ${ }^{29}$ Their capability for glycosylation and proper protein processing offers advantages for these applications. ${ }^{30}$

As indicated above, many decades of research have led to the use of filamentous fungal production hosts (cell factories) in modern industrial biotechnology. These strains have been selected and highly adapted to the specific conditions of the processes to which they are applied. The interplay between the physical and chemical parameters of a production process and the biological properties of the cell complicate cell-factory selection. ${ }^{31}$ Morphology also poses a challenge due to the filamentous nature of the growth and the differentiation of cellular compartments as hyphae extend. ${ }^{32,33}$ This leads to heterogeneity in terms of the morphological forms present and the cell (compartment) types that contribute to the overall performance of the culture. ${ }^{34}$ The challenge is to balance cellular potential, process design, and economic feasibility. High broth viscosities, and thus low oxygen mass transfer, are the main physical factors governing protein productivity in filamentous fungal cultivations. These have been optimized by applying specific feeding strategies to improve glucoamylase production by both $A$. oryzae and A. niger. ${ }^{11,35}$
Based on these considerations, and with a focus on the cellular biology, the characteristics of desirable filamentous fungal cell factories are summarized in Table 1, with the listed advantages driven by process economics and the need for viable large-scale operation. ${ }^{36}$

\section{IMPROVING CELL FACTORIES}

To improve our understanding of established cell factories in expanded applications, or to extend novel fungal species to the realm of industrial biotechnology, methodologies to ensure that analyses can be performed accurately on cells arising from specific and controlled cultivation environments need to be developed. Cellular performance is the term used to define the capabilities of a cell under a specific set of cultivation conditions; it facilitates the comparison and evaluation of different species or differing conditions. Classical parameters of physiological characterization — growth rate, yield, and productivity estimationare the cornerstone of cellular performance assessment.

Metabolic engineering has enabled significant improvements in cell factory efficiency by targeting and examining the effects of genetic modifications that lead to improved cell factory characteristics. ${ }^{37-39}$ In multiple rounds of strain design, genetic modification and analysis of the resulting cellular physiology have led to sequential improvement and led to filamentous fungi as highly efficient cell factories. The directed approaches of metabolic engineering have been the main strategy for tackling substrateutilization issues, improving product yield, eliminating unwanted by-products, and introducing or extending metabolic pathways. The product spectrum continues to expand as processing knowhow and understanding of cellular physiology improves. ${ }^{40-45}$ To this end, metabolic models, control analysis, and flux analysis using ${ }^{13} \mathrm{C}$-labelled substrates have been employed for benchmarking strains and quantifying the consequences of genetic modifications on metabolism. ${ }^{4-52}$ These approaches were developed and established before genome sequences were available, but are still valid in the post-genome era.

\begin{tabular}{|c|c|}
\hline $\begin{array}{l}\text { DESIRABLE CELL-FACTORY } \\
\text { CHARACTERISTICS }\end{array}$ & ADVANTAGES \\
\hline Efficient substrate utilization & Lower production costs \\
\hline Wide substrate range & $\begin{array}{l}\text { Tunable process in terms of substrate } \\
\text { availability }\end{array}$ \\
\hline $\begin{array}{l}\text { High degree of product secretion and } \\
\text { product stabilization }\end{array}$ & Ease of downstream processing \\
\hline High yield and productivity & Increased profit margin of process \\
\hline Minimized by-product formation & $\begin{array}{l}\text { Simplified product recovery and } \\
\text { improved process economy }\end{array}$ \\
\hline $\begin{array}{l}\text { Morphology suited for bioreactor pro- } \\
\text { cesses }\end{array}$ & $\begin{array}{l}\text { Preferred morphology depending on } \\
\text { product; simplified process operation }\end{array}$ \\
\hline Amenable to genetic modification & Targeted alterations can be achieved \\
\hline
\end{tabular}


Non-direct approaches, such as evolutionary engineering, can also be applied when substrate tolerance or product toxicity are an issue. ${ }^{53}$ While these techniques are well established for yeast-particularly with regard to mixed sugar utilization-to our knowledge, applications in filamentous fungi have not yet been demonstrated. ${ }^{54,55}$

Even in modern fungal biotechnology, basic approaches to parameter estimation are still the foundation for most quantitative fungal physiology studies. The standard for detailed physiological characterization was set in the late 1990s and is exemplified in studies that employ different cultivation modes to study various physiological states. ${ }^{56-58}$ Such studies provided highly reproducible data on growth rates, yield coefficients, and productivity, allowing an assessment of conditions for optimal cellular performance.

As highlighted above, metabolic engineering is a useful systematic method in which strains are constructed through genetic engineering with the aim of introducing/improving desirable cell factory characteristics (Table 1). However, cellular robustness, derived from enzyme redundancies and complex regulatory circuits, often enables the cell to counteract the genetic modifications. For this reason, systems biology approaches have become increasingly popular to assist in the identification of targets for genetic engineering. The increasing number of available genomes in particular has enabled the shift to data integration from several omics techniques, which facilitates a holistic view of cellular functions. Omics-driven analyses are rapidly becoming an essential approach to evaluation of genetic regulation that underlies quantified metabolic responses.

\section{Omics-Driven Cell Factory Characterization}

Systems biology approaches for cell factory characterization of filamentous fungi that incorporate gene expression analysis are rapidly emerging. ${ }^{39,59-61}$ This section will, therefore, concentrate on genome-wide analyses and the integration of transcriptomics data with physiological characterization in submerged cultivations. An overview of selected studies is provided in Table 2.9,62-84 Omics studies that have investigated desirable cell factory characteristics can be broadly grouped into three categories: efficient carbon utilization; high yield; and efficient product secretion. Aspergilli are known for their ability to utilize a broad range of substrates and to use these substrates efficiently. They are also able to maximize their energy production through the stringent coordination of regulatory networks for carbon-source utilization. Fungal cultivation physiology coupled with transcriptomics has been used to provide valuable insight into regulatory responses caused by single substrates, combinations of substrates, and complex carbon substrates.

\section{EFFICIENT CARBON UTILIZATION}

Bioconversion of a wider range of substrates is becoming increasingly relevant as biosustainability becomes a requirement in process design. Transcriptomics also has an important role to play in the identification of genes required for efficient catabolism of carbon sources present in complex and waste substrates. ${ }^{68,71-74}$ Due to the abundance of xylose in hemicel- lulose, the regulatory mechanisms involved in using this carbon source as opposed to glucose have been investigated in three different Aspergilli. One study developed and validated a method for transcriptome analysis of Aspergilli, and allowed identification of conserved gene responses to growth on glucose and xylose in $A$. niger, $A$. oryzae, and $A$. nidulans. ${ }^{85}$ This technique was used to provide a comparison of $A$. oryzae and $A$. niger growing on maltose, which is utilized in industrial processes as an effective inducer of enzyme production. ${ }^{69}$ The study illustrated the routes for maltose transport and metabolism and revealed how maltose may affect gene expression, pointing toward targets for improved protein secretion. In another study, glycerol metabolism was investigated in three Aspergillus species, leading to the identification of possible regulatory binding sites, as well as giving insights into crossspecies evolution. ${ }^{73}$

Carbon catabolite repression, the regulatory mechanism that controls carbon utilization, is mediated by transcription factor regulators, including the CreA protein. In one of the first studies to employ a DNA microarray of an Aspergillus species, transcription analysis of wild type and creA mutant $A$. nidulans strains was performed, and growth on glucose and ethanol was compared. ${ }^{86}$ This work gave an overview of the global response caused by CreA and highlighted the advantage of large-scale transcriptional analysis for studying broadly acting transcriptional regulators such as CreA (Table 2).

\section{HIGH YIELD AND IMPROVED PRODUCT SECRETION}

High yield and efficient secretion capacity are key criteria when expression hosts are being considered for an industrial process. In a study to assess the physiological characterization of A. niger grown in chemostats with xylose or maltose as the limiting substrate and growth controlled at the same rate. ${ }^{80}$ The data obtained included transcription profiles and an estimation of quantitative physiological parameters. The increased secretion potential on maltose was related to the induced transcription of more than 90 genes that regulate protein secretion, leading to the identification of putative regulatory elements and a greater understanding of the secretory pathway in filamentous fungi.

High-yielding strains have also been the subject of transcriptomics studies investigating the response of process physiology to protein over-expression. One example is a study on the effect of glucoamylase over-expression in maltose-limited chemostats through transcriptomics. ${ }^{80}$ A notable finding was the identification of a set of only 40 differentially expressed core genes that ensure high protein traffic through the secretory pathway. In a study of $T$. reesei, gene expression was correlated to protein production rate in chemostat cultures at a range of specific growth rates. ${ }^{78}$ This work allowed for the identification of biosynthetic activities with positive and negative effects on protein production and indicated possible regulatory mechanisms in the observed physiological responses.

While studies on Aspergilli and $T$. reesei have centered on carbon metabolism and productivity, Penicillium research has focused on secondary metabolite production, with emphasis on the biosynthetic pathways and product spectrum expansion (Table 2). 


\section{Table 2. Overview of Omics-Driven Cell Factory Characterization in Filamentous Fungi} STRAIN AIM OF STUDY CULTIVATION TYPE

OMICS APPLIED

$\beta$-Lactam Production

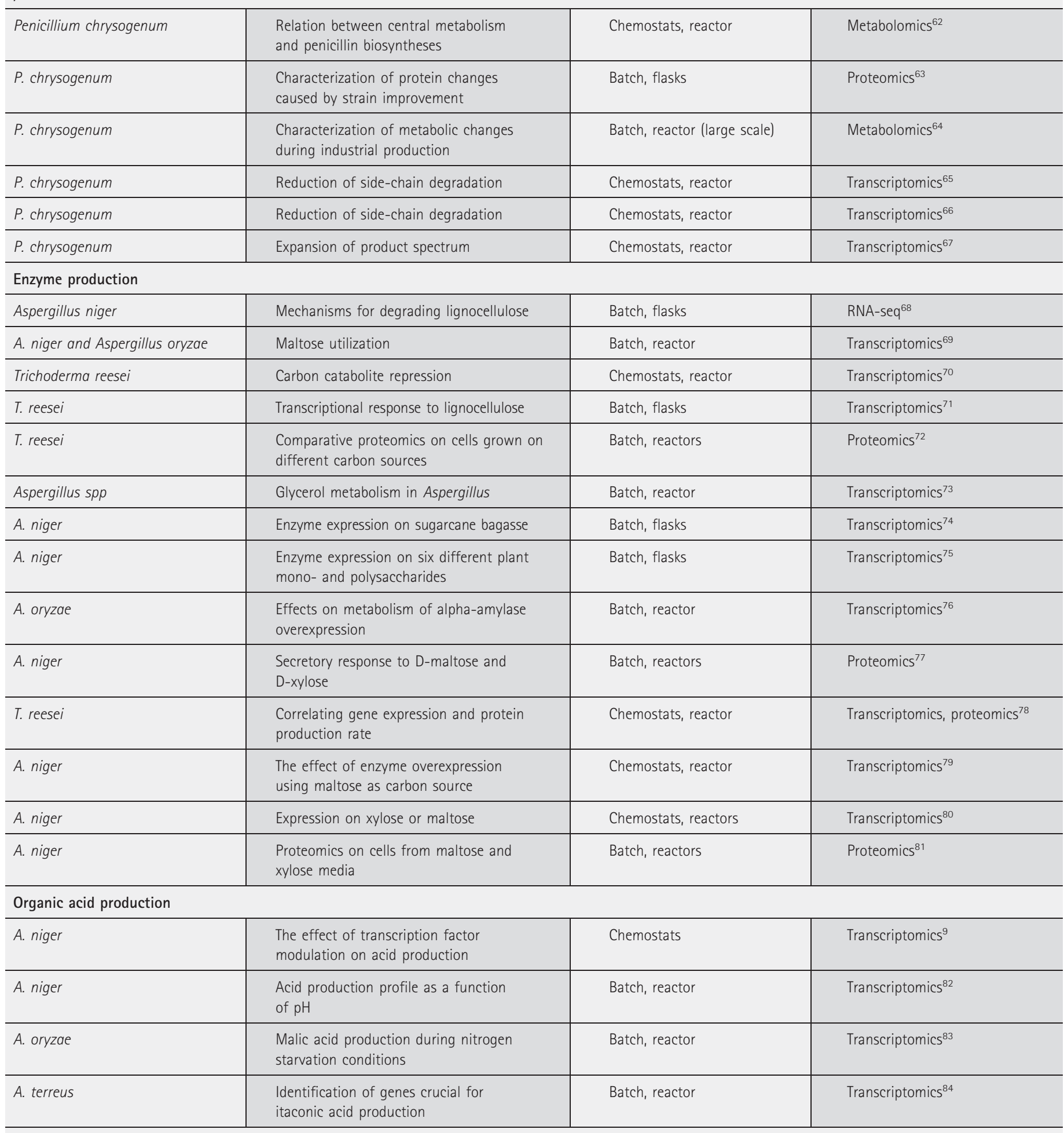




\section{TAILOR-MADE BIOMASS FOR OMICS ANALYSES}

The common factor in the omics-driven cell factory analysis studies reviewed above is the controlled cultivation techniques that produce tailor-made biomass specifically for the various approaches employed. Obtaining biomass through standardized cultivations in bioreactors, where the physiological parameters can be estimated and integrated with omics data, is a growing trend. It must be stressed that the quality of the omics data depends on the quality and reproducibility of the cultivations, which provide an accurate snapshot of metabolism at a given point in time and have definable physical, chemical, and physiological conditions.

Figure 1 outlines the boundaries and interplay between the various approaches that are useful for investigating and quantifying the cellular performance of industrially relevant microorganisms. Quantitative physiology still forms the knowledgebase in terms of overall culture performance, and essentially directs selection of the biomass for further characterization of strains. This biomass can be utilized directly in omics analyses, but it is often advantageous to employ strain modification in one or more rounds of metabolic engineering before analyses are performed. In this extended cycle, systems biology techniques allow for data integration of all analyses with genome sequences, and models can form the basis for predicting targets for further improvement in cellular performance.

Previous studies have relied mainly on batch or continuous culture to obtain biomass for omics analysis. However, the use of state-of-the-art controlled cultivations in combination with omics has found an important role in work employing reproducible carbon- and energy-limited retentostat cultures. These have been applied to study the transcriptional response of $A$. niger at growth rates approaching zero. ${ }^{80}$ Related studies by the same group focused on carbon starvation and showed a corre-

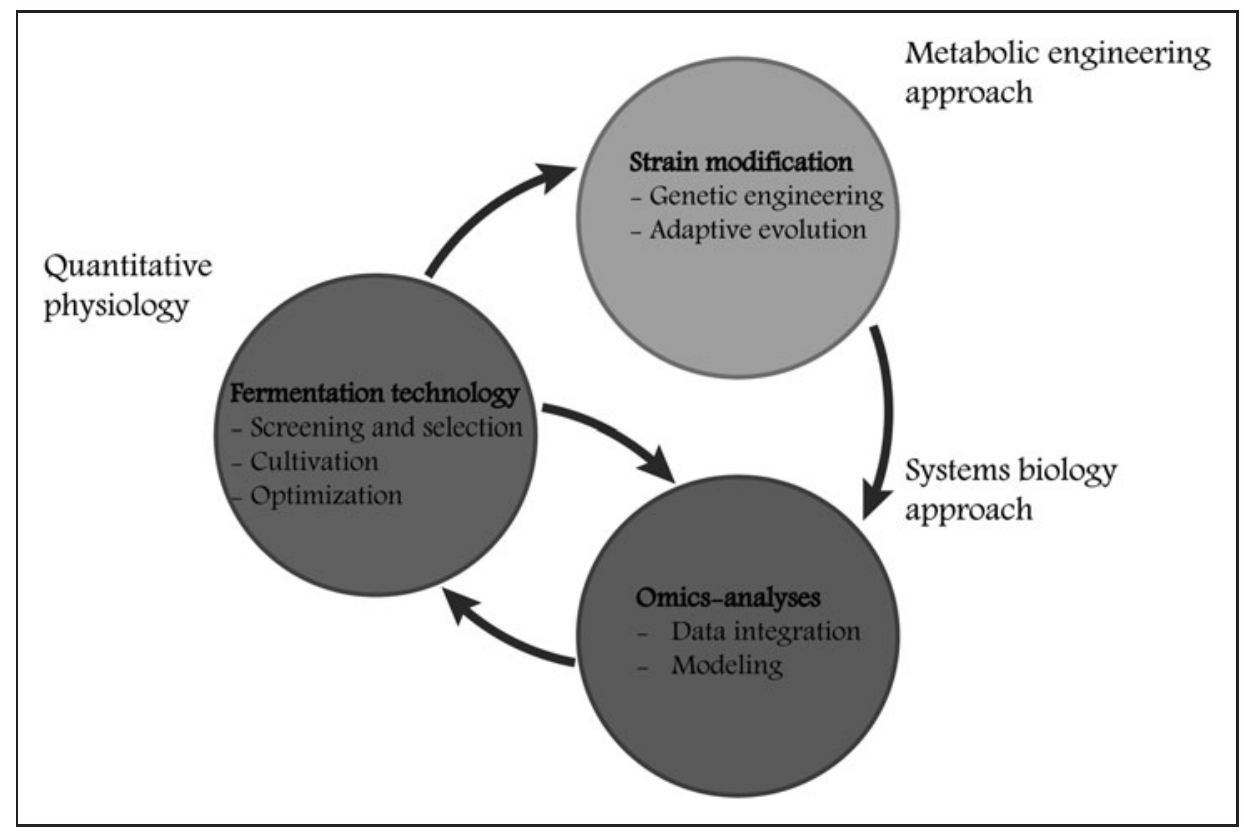

Fig. 1. The boundaries and interplay between quantitative physiology, metabolic engineering, and systems biology approaches in analysis of cell factory performance. lation between transcriptomics analysis and the morphological development of the culture-leading to the proposition of a model for the carbon starvation response of A. niger. ${ }^{10}$

While integration of process data, physiological characterization, and transcriptomics analysis is well advanced, further application of the knowledge gained from genome-wide analyses should be the next goal for systems biology approaches in filamentous fungi. Increasing the scale of data integration efforts to combine more systems biology disciplines, such as pathway reconstruction, metabolomics, metabolic flux analysis, proteomics, and transcriptomics-as opposed to the currently predominant single-methodology studies-is required to move to a systemic understanding of cell factories. Substantial leaps forward could also be made by more efficiently utilizing the omics data already available and applying this information to make targeted improvements in cell factories already employed in industrial processes. A particularly overlooked aspect of filamentous fungi is the complexity derived from their essentially multicellular nature, which could benefit greatly from targeted multi-omics efforts to develop completely designable and customizable submerged bioreactor cultivations.

\section{Conclusions}

Systems biology approaches based on tailor-made biomass from highly controlled cultivations are now established, and, combined with the development of advanced techniques and tools for studying cellular performance, can provide a deeper understanding of potential uses of filamentous fungi in industrially relevant processes. We predict that the next decade of research on these complex cell factories will see significant advancements. In particular, the integration of omics-based technologies will drive substantial development in our ability to customize fungal cell factories and their processes. Increased knowledge of cellular performance will allow these processes to be more tunable, as it becomes increasingly possible to modify cultivation parameters and in wider intervals than used in currently employed processes.

Furthermore, we believe that the native product diversity within filamentous fungi should be further exploited to bring forward new candidates with potential applications in biosustainable processes. In addition to the ongoing discovery of new enzymes for the degradation of complex biomass, the field can move further into the conversion of complex substrates into new value-added products from fungal secondary metabolism, e.g., pigments and flavor compounds.

The current and future impact that the reduced cost of genome sequencing has had in advancing applications of filamentous fungi cannot be overstated. 


\section{WORKMAN, ANDERSEN, AND THYKAER}

Access to the genome sequence of the cell factory of choice greatly extends the possibilities of physiological characterization and analysis with all omics-derived technologies. The ability to sequence more fungal genomes generates the possibility of new heterologous products from both enzymes and fungal metabolism. The ways in which genome sequencing are being employed have also started to change the traditional industrial biotechnology approaches to mutation/selection cycles. This method has proven highly effective for generating efficient producer strains, and can now be further rationalized with backsequencing to identify beneficial mutations for reinsertion into platform strains.

In conclusion, we find that cellular performance evaluation and characterization should focus on multicellular physiology and the development of reliable screening assays and methods for detailed characterization using omics and high-throughput analytical methods. If this is accomplished, fungal cell factories and processes can become highly customizable, utilize fungal bioproduct diversity to its full potential, and reduce the timeframe from product discovery to industrial production.

\section{Author Disclosure Statement}

The authors declare no competing financial interests exist.

\section{REFERENCES}

1. Goffeau A, Barrell BG, Bussey H, et al. Life with 6000 genes. Science 1996;274(5287):546,563-567.

2. Blattner FR, Plunkett $G$, Bloch $C A$, et al. The complete genome sequence of Escherichia coli K-12. Science 1997;277(5331):1453-1462.

3. de Jong B, Siewers V, Nielsen J. Systems biology of yeast: Enabling technology for development of cell factories for production of advanced biofuels. Curr Opin Biotechnol 2012;23(4):624-630.

4. Galagan JE, Calvo SE, Borkovich KA, et al. The genome sequence of the filamentous fungus Neurospora crassa. Nature 2003;422(6934):859-868.

5. Machida M, Asai $K$, Sano $M$, et al. Genome sequencing and analysis of Aspergillus oryzae. Nature 2005;438(7071):1157-1161.

6. Pel HJ, de Winde JH, Archer DB, et al. Genome sequencing and analysis of the versatile cell factory Aspergillus niger CBS 513.88. Nat Biotechnol 2007;25(2):221-231.

7. Martinez D, Berka RM, Henrissat B, et al. Genome sequencing and analysis of the biomass-degrading fungus Trichoderma reesei (syn. Hypocrea jecorina). Nat Biotechnol 2008;26(5):553-560.

8. van den Berg MA, Albang R, Albermann $K$, et al. Genome sequencing and analysis of the filamentous fungus Penicillium chrysogenum. Nat Biotechnol 2008;26(10):1161-1168.

9. Poulsen $L$, Andersen $M R$, Lantz $A E$, et al. Identification of a transcription factor controlling $\mathrm{pH}$-dependent organic acid response in Aspergillus niger. PLoS One 2012;7(12):e50596

10. Nitsche BM, Jorgensen TR, Akeroyd $M$, et al. The carbon starvation response of Aspergillus niger during submerged cultivation: Insights from the transcriptome and secretome. BMC Genomics 2012;13:380.

11. Pedersen L, Hansen $K_{1}$ Nielsen J, et al. Industrial glucoamylase fed-batch benefits from oxygen limitation and high osmolarity. Biotechnol Bioeng 2012;109(1):116-124.

12. Lo CM, Zhang Q, Callow NV, et al. Cellulase production by continuous culture of Trichoderma reesei Rut C30 using acid hydrolysate prepared to retain more oligosaccharides for induction. Bioresour Technol 2010;101(2):717-723.

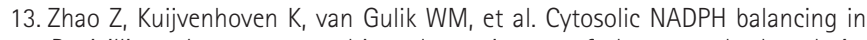
Penicillium chrysogenum cultivated on mixtures of glucose and ethanol. Appl Microbiol Biotechnol 2011;89(1):63-72.

14. Gibbs PA, Seviour RJ, Schmid F. Growth of filamentous fungi in submerged culture: Problems and possible solutions. Crit Rev Biotechnol 2000;20(1):17-48.

15. Kubicek CP, Punt $P$, Visser J. Production of organic acids by filamentous fungi. In: Osiewacz HD, ed. The Mycota 10. Industrial Applications. Berlin, SpringerVerlag 2010:215-234.

16. van den Berg MA. Impact of the Penicillium chrysogenum genome on industrial production of metabolites. Appl Microbiol Biotechnol 2011;92(1):45-53.

17. Steiger MG, Blumhoff ML, Mattanovich $D$, et al. Biochemistry of microbial itaconic acid production. Front Microbiol 2013;4:23.

18. Ward OP. Production of recombinant proteins by filamentous fungi. Biotechnol Adv 2012;30(5):1119-1139.

19. Legisa M, Mattey M. Changes in primary metabolism leading to citric acid overflow in Aspergillus niger. Biotechnol Lett 2007;29(2):181-190.

20. Magnuson JK, Lasure L. Organic acid production by filamentous fungi. In: Tkacz JS, Lange L, eds. Advances in Fungal Biotechnology for Industry, Agriculture, and Medicine. New York, NY: Kluwer Academic/Plenum Publishers, 2004:307340.

21. Papagianni M. Advances in citric acid fermentation by Aspergillus niger: Biochemical aspects, membrane transport and modeling. Biotechnol Adv 2007;25(3):244-263.

22. Thykaer J, Nielsen J. Metabolic engineering of beta-lactam production. Metab Eng 2003;5(1):56-69.

23. Bruggink A, Roy PD. Industrial synthesis of semisynthetic antibiotics. In: Bruggink $A$, ed. Synthesis of $\beta$-Lactam Antibiotics, Chemistry, Biocatalysis and Process Integration. Dordrecht, The Netherlands: Kluwer Acadenic Publishers, 2001:13-56.

24. Elander RP. Industrial production of $\beta$-lactam antibiotics. App/ Microbiol Biotechnol 2003;61(5-6):385-392.

25. Schuster A, Schmoll M. Biology and biotechnology of Trichoderma. Appl Microbiol Biotechnol 2010;87(3):787-799.

26. Rokem JS, Lantz AE, Nielsen J. Systems biology of antibiotic production by microorganisms. Nat Prod Rep 2007;24(6):1262-1287.

27. Hakkinen $M$, Arvas $M, O j a ~ M$, et al. Re-annotation of the CAZy genes of Trichoderma reesei and transcription in the presence of lignocellulosic substrates. Microb Cell Fact 2012;11:134.

28. Lein J. The Panlabs penicillin strain improvement program. In: Vanek Z, Hostálek Z, eds. Overproduction of Microbial Metabolites. Boston, MA: Butterworths, 1986:105-139.

29. AMFEP. Association of manufacturers and formulators of enzyme products. (2009) Available at: http://amfep.org/content/list-enzymes (Last accessed August 2013).

30. Punt PJ, van Biezen N, Conesa A, et al. Filamentous fungi as cell factories for heterologous protein production. Trends Biotechnol 2002;20(5):200-206.

31. Fazenda ML, Dias JM, Harvey LM, et al. Towards better understanding of an industrial cell factory: Investigating the feasibility of real-time metabolic flux analysis in Pichia pastoris. Microb Cell Fact 2013;12:51.

32. McIntyre M, Muller $C$, Dynesen J, et al. Metabolic engineering of the morphology of Aspergillus. Adv Biochem Eng Biotechnol 2001;73:103-128.

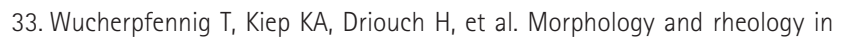
filamentous cultivations. Adv App/ Microbiol 2010;72:89-136.

34. McIntyre M, Eade JK, Cox PW, et al. Quantification of autolysis in Penicillium chrysogenum by semiautomated image analysis. Can J Microbiol 2001;47(4):315-321.

35. Bhargava S, Wenger KS, Marten MR. Pulsed addition of limiting-carbon during Aspergillus oryzae fermentation leads to improved productivity of a recombinant enzyme. Biotechnol Bioeng 2003;82(1):111-117. 


\section{CELLULAR PERFORMANCE OF FILAMENTOUS FUNGI}

36. Nielsen J. Metabolic engineering. App/ Microbiol Biotechnol 2001;55(3):263283.

37. Bailey JE. Toward a science of metabolic engineering. Science 1991;252(5013):1668-1675.

38. Nielsen J. Metabolic engineering: Techniques for analysis of targets for genetic manipulations. Biotechnol Bioeng 1998;58(2-3):125-132.

39. Papini M, Salazar M, Nielsen J. Systems biology of industrial microorganisms. Adv Biochem Eng Biotechnol 2010;120:51-99.

40. Prathumpai $W$, McIntyre $M$, Nielsen J. The effect of CreA in glucose and xylose catabolism in Aspergillus nidulans. Appl Microbiol Biotechnol 2004;63(6):748753.

41. de Jongh WA, Nielsen J. Enhanced citrate production through gene insertion in Aspergillus niger. Metab Eng 2008;10(2):87-96.

42. Theilgaard $H$, van Den Berg $M$, Mulder $C$, et al. Quantitative analysis of Penicillium chrysogenum Wis54-1255 transformants overexpressing the penicillin biosynthetic genes. Biotechnol Bioeng 2001;72(4):379-388.

43. Pedersen $H_{1}$ Christensen $B_{1}$ Hjort $C_{\text {, }}$ et al. Construction and characterization of an oxalic acid nonproducing strain of Aspergillus niger. Metab Eng 2000;2(1):34-41.

44. Blumhoff ML, Steiger MG, Mattanovich D, et al. Targeting enzymes to the right compartment: Metabolic engineering for itaconic acid production by Aspergillus niger. Metab Eng 2013;19C:26-32.

45. Robin J, Jakobsen M, Beyer M, et al. Physiological characterisation of Penicillium chrysogenum strains expressing the expandase gene from Streptomyces clavuligerus during batch cultivations. Growth and adipoyl-7aminodeacetoxycephalosporanic acid production. Appl Microbiol Biotechnol 2001;57(3):357-362.

46. Prathumpai $W$, Gabelgaard JB, Wanchanthuek $P$, et al. Metabolic control analysis of xylose catabolism in Aspergillus. 2003; Biotechnol Prog 19 (4):1136-1141.

47. de Groot MJ, Prathumpai W, Visser J, et al. Metabolic control analysis of Aspergillus niger L-arabinose catabolism. Biotechnol Prog 2005;21(6):1610-1616.

48. Theilgaard HA, Nielsen J. Metabolic control analysis of the penicillin biosynthetic pathway: The influence of the LLD-ACV:bisACV ratio on the flux control. Antonie Van Leeuwenhoek 1999;75(1-2):145-154.

49. David $H$, Krogh AM, Roca $C$, et al. CreA influences the metabolic fluxes of Aspergillus nidulans during growth on glucose and xylose. Microbiology 2005;151(Pt 7):2209-2221.

50. Kleijn RJ, Liu F, van Winden WA, et al. Cytosolic NADPH metabolism in penicillin-G producing and non-producing chemostat cultures of Penicillium chrysogenum. Metab Eng 2007;9(1):112-123.

51. Christensen B, Thykaer J, Nielsen J. Metabolic characterization of high- and low-yielding strains of Penicillium chrysogenum. Appl Microbiol Biotechnol 2000;54(2):212-217.

52. Thykaer J, Christensen B, Nielsen J. Metabolic network analysis of an adipoyl-7ADCA-producing strain of Penicillium chrysogenum: Elucidation of adipate degradation. Metab Eng 2002;4(2):151-158.

53. Sauer U. Evolutionary engineering of industrially important microbial phenotypes. Adv Biochem Eng Biotechnol 2001;73:129-169.

54. Kuyper M, Toirkens MJ, Diderich JA, et al. Evolutionary engineering of mixedsugar utilization by a xylose-fermenting Saccharomyces cerevisiae strain. FEMS Yeast Res 2005;5(10):925-934.

55. Garcia Sanchez R, Karhumaa K, Fonseca C, et al. Improved xylose and arabinose utilization by an industrial recombinant Saccharomyces cerevisiae strain using evolutionary engineering. Biotechnol Biofuels 2010;3:13.

56. Morkeberg R, Carlsen $M$, Nielsen J. Induction and repression of alpha-amylase production in batch and continuous cultures of Aspergillus oryzae. Microbiology 1995;141(Pt 10):2449-2454

57. Pedersen $H$, Beyer M, Nielsen J. Glucoamylase production in batch, chemostat and fed-batch cultivations by an industrial strain of Aspergillus niger. Appl Microbiol Biotechnol 2000;53(3):272-277
58. van Gulik WM, de Laat WT, Vinke JL, et al. Application of metabolic flux analysis for the identification of metabolic bottlenecks in the biosynthesis of penicillinG. Biotechnol Bioeng 2000;68(6):602-618.

59. Knuf C, Nielsen J. Aspergilli: Systems biology and industrial applications. Biotechnol J 2012;7(9):1147-1155

60. Kubicek CP. Systems biological approaches towards understanding cellulase production by Trichoderma reesei. J Biotechnol 2013;163(2):133-142.

61. Meyer V, Wu B, Ram AF. Aspergillus as a multi-purpose cell factory: Current status and perspectives. Biotechnol Lett 2011;33(3):469-476.

62. Nasution U, van Gulik WM, Ras C, et al. A metabolome study of the steadystate relation between central metabolism, amino acid biosynthesis and penicillin production in Penicillium chrysogenum. Metab Eng 2008;10(1):10-23.

63. Jami MS, Barreiro C, Garcia-Estrada C, et al. Proteome analysis of the penicillin producer Penicillium chrysogenum: Characterization of protein changes during the industrial strain improvement. Mol Cell Proteomics 2010;9(6):1182-1198.

64. Ding MZ, Lu H, Cheng JS, et al. Comparative metabolomic study of Penicillium chrysogenum during pilot and industrial penicillin fermentations. Appl Biochem Biotechnol 2012;168(5):1223-1238.

65. Veiga $T$, Gombert AK, Landes $N$, et al. Metabolic engineering of $\beta$-oxidation in Penicillium chrysogenum for improved semi-synthetic cephalosporin biosynthesis. Metab Eng 2012;14(4):437-448.

66. Harris DM, van der Krogt ZA, Klaassen $P$, et al. Exploring and dissecting genome-wide gene expression responses of Penicillium chrysogenum to phenylacetic acid consumption and penicillin G production. BMC Genomics 2009;10:75.

67. Harris DM, Westerlaken I, Schipper D, et al. Engineering of Penicillium chrysogenum for fermentative production of a novel carbamoylated cephem antibiotic precursor. Metab Eng 2009;11(2):125-137.

68. Delmas S, Pullan ST, Gaddipati S, et al. Uncovering the genome-wide transcriptional responses of the filamentous fungus Aspergillus niger to lignocellulose using RNA sequencing. PLoS Genet 2012;8(8):e1002875.

69. Vongsangnak W, Salazar M, Hansen $K_{1}$ et al. Genome-wide analysis of maltose utilization and regulation in aspergilli. Microbiology 2009;155(Pt 12):3893-3902.

70. Portnoy T, Margeot $A$, Linke $R$, et al. The CRE1 carbon catabolite repressor of the fungus Trichoderma reesei: A master regulator of carbon assimilation. BMC Genomics 2011:12:269.

71. Ries L, Pullan ST, Delmas S, et al. Genome-wide transcriptional response of Trichoderma reesei to lignocellulose using RNA sequencing and comparison with Aspergillus niger. BMC Genomics 2013;14:541.

72. Jun $H$, Guangye $H$, Daiwen $C$. Insights into enzyme secretion by filamentous fungi: Comparative proteome analysis of Trichoderma reesei grown on different carbon sources. J Proteomics 2013;89:191-201.

73. Salazar $M$, Vongsangnak W, Panagiotou $G$, et al. Uncovering transcriptional regulation of glycerol metabolism in Aspergilli through genome-wide gene expression data analysis. Mol Genet Genomics 2009;282(6):571-586.

74. de Souza WR, de Gouvea PF, Savoldi M, et al. Transcriptome analysis of Aspergillus niger grown on sugarcane bagasse. Biotechnol Biofuels 2011;4:40.

75. Andersen MR, Giese $M$, de Vries RP, et al. Mapping the polysaccharide degradation potential of Aspergillus niger. BMC Genomics 2012;13:313.

76. Vongsangnak W, Hansen K, Nielsen J. Integrated analysis of the global transcriptional response to alpha-amylase over-production by Aspergillus oryzae. Biotechnol Bioeng 2011;108(5):1130-1139.

77. de Oliveira JM, van Passel MW, Schaap PJ, et al. Proteomic analysis of the secretory response of Aspergillus niger to D-maltose and D-xylose. PLoS One 2011;6(6):e20865.

78. Arvas M, Pakula T, Smit B, et al. Correlation of gene expression and protein production rate-a system wide study. BMC Genomics 2011;12:616.

79. Kwon MJ, Jorgensen TR, Nitsche BM, et al. The transcriptomic fingerprint of glucoamylase over-expression in Aspergillus niger. BMC Genomics 2012;13:701. 


\section{WORKMAN, ANDERSEN, AND THYKAER}

80. Jorgensen TR, Goosen T, Hondel CA, et al. Transcriptomic comparison of Aspergillus niger growing on two different sugars reveals coordinated regulation of the secretory pathway. BMC Genomics 2009;10:44.

81. Lu X, Sun J, Nimtz M, et al. The intra- and extracellular proteome of Aspergillus niger growing on defined medium with xylose or maltose as carbon substrate. Microb Cell Fact 2010;9:23.

82. Andersen MR, Lehmann L, Nielsen J. Systemic analysis of the response of Aspergillus niger to ambient pH. Genome Biol 2009;10(5):R47.

83. Knuf C, Nookaew I, Brown SH, et al. Investigation of malic acid production in Aspergillus oryzae under nitrogen starvation conditions. Appl Environ Microbiol 2013; 79(19):6050-6058.

84. Li $A$, van Luijk $N$, ter Beek $M$, et al. A clone-based transcriptomics approach for the identification of genes relevant for itaconic acid production in Aspergillus. Fungal Genet Biol 2011;48(6):602-611.

85. Andersen MR, Vongsangnak W, Panagiotou G, et al. A trispecies Aspergillus microarray: Comparative transcriptomics of three Aspergillus species. Proc Natl Acad Sci 2008;105(11):4387-4392.
86. Mogensen J, Nielsen HB, Hofmann G, et al. Transcription analysis using highdensity micro-arrays of Aspergillus nidulans wild-type and creA mutant during growth on glucose or ethanol. Fungal Genet Biol 2006;43(8):593-603.

Address correspondence to:

Jette Thykaer, PhD

Associate Professor

Department of Systems Biology

Technical University of Denmark Building 223, Sфltofts Plads, Kgs 2800 Lyngby

Denmark

Phone: + 45 (0) 45252584

Fax: +45 (0) 884148

E-mail: jt@bio.dtu.dk 